\title{
Photometric Determination of Tungsten in Steel and Titanium Alloys With Dithiol
}

\author{
Lawrence A. Machlan and John L. Hague
}

\begin{abstract}
A method is described for the direct photometric determination of tungsten in steels. The sample, 0.1 to $0.2 \mathrm{~g}$ in weight, is dissolved in aqua regia, and a sulfuric-phosphoricperchloric acid mixture is added. The solution is evaporated to fumes of sulfuric acid and diluted to volume with diluted sulfuric acid $(1+3)$. An aliquot portion of the solution is treated with dithiol in diluted sulfuric acid solution $(1+3)$ containing sulfur dioxide, and molybdenum and certain other potential interferences are removed by extraction with chloroform. Copper and other elements forming insoluble dithiolates are removed by filtration. The tungsten-dithiol complex is then formed, after the addition of hydrochloric acid, stannous chloride, and dithiol, and extracted with butyl acetate. The absorbancy of the tungsten complex is determined at approximately $635 \mathrm{~m} \mu$. An accuracy of 0.005 percent of tungsten, or better, is indicated in the range 0.05 to 0.50 percent of tungsten, and of about 0.001 percent for amounts of less than 0.05 percent of tungsten. The application of the method to titanium alloys is described in an appendix section.
\end{abstract}

\section{Introduction}

Tungsten is finding an increased usage, in the range of 2 percent or less, as an alloying element in ferrous metallurgy. Typical of some of these alloys are the "nondeforming" die and chisel steels (usually carbon-chromium-tungsten alloys), agehardening chromium-nickel-tungsten alloys, lowtungsten tool steels such as the AISI types M 1 and M 7, and alloys finding application in the hightemperature field such as the 19-9DL types of stainless steels. Aside from alloy addition, many steels, through the use of scrap, contain residual amounts of tungsten, which may vary from a few thousandths to several tenths of a percent.

Gravimetric procedures are not well adapted to the determination of small percentages of tungsten. Iron and molybdenum retard the precipitation of small quantities of tungsten by the usual cinchonine procedure. Titanium, niobium, tin, and tantalum are often encountered, and any procedure devised must provide for their presence. Of the reactions available for the photometric determination of tungsten, the most commonly employed are those that use thiocyanate, hydroquinone, and dithiol as reagents. The thiocyanate reaction $[5]^{1}$ has found acceptance $[11,12]$ primarily for the analysis of tool steels, but some interference is encountered with molybdenum and vanadium. The hydroquinone reaction has been used in the Bureau's Analytical Chemistry Section for some years in combination with an alpha-benzoinoxime precipitation [8], but difficulties are encountered when niobium is present. In fact, the color has been recommended [9] for the determination of niobium and tungsten in stainless steel, using photometric measurements at two different wavelengths. In any case, titanium [10] gives a much more intense color and provides a serious interference.

The dithiol (1,2-dithiol-4-methylbenzene) reagent $[7,13]$ appeared to offer advantages for the determination of low percentages of tungsten in spite of

\footnotetext{
1 Figures in brackets indicate the literature references at the end of this paper.
}

its obnoxious odor. Potential interferences are few, and most of these can be removed, with the same reagent, under conditions such that the tungsten color does not develop. This reagent has been applied to the determination of tungsten in titanium metal [18], in tantalum, titanium, and zirconium metals [6], and in steel [3, 14, 16, 19].

The method presented here is the result of a study of the conditions necessary to make the reaction specific for tungsten in the presence of the large number of elements encountered in ferrous metallurgical analysis. A clear solution of the sample in a sulfuric-phosphoric acid mixture can be obtained by a simple fuming operation. The resulting solution is well adapted $[1,4,17]$ for the removal of molybdenum, the principal interfering element, with dithiol because considerable variations in acidity and temperature can be tolerated without tungsten reacting. Dithiol solution is added; the molybdenum and other elements that form soluble complexes are extracted with chloroform. The insoluble complexes, primarily copper, are removed by filtration. Hydrochloric acid, stannous chloride solution containing a trace of copper, and dithiol are added, and the tungsten-dithiol color is developed by heating the solution for 10 minutes on a steam bath. The solution is cooled, and the tungsten complex extracted with butyl acetate. The absorbancy of the extract is measured at $635 \mathrm{~m} \mu$ and the tungsten determined by reference to a calibration curve or table.

The present method will not compete timewise with spectrographic methods. It was designed to provide values for tungsten, in the range 0.001 to 0.5 percent, for the standardization of a group of spectrographic steel standards containing additions of 22 elements and the rare earths. A single determination can be carried through in several hours; a group of eight determinations can be completed in a day.

\section{Apparatus}

Colorimeter. An Evelyn type of colorimeter, including filters, voltage stabilizer, and galvanometer 
was used for the quantitative measurements reported. Matched test tubes (22 by $175 \mathrm{~mm}$ ) were used as absorption cells.

Filtering Arrangement. See figure 1.

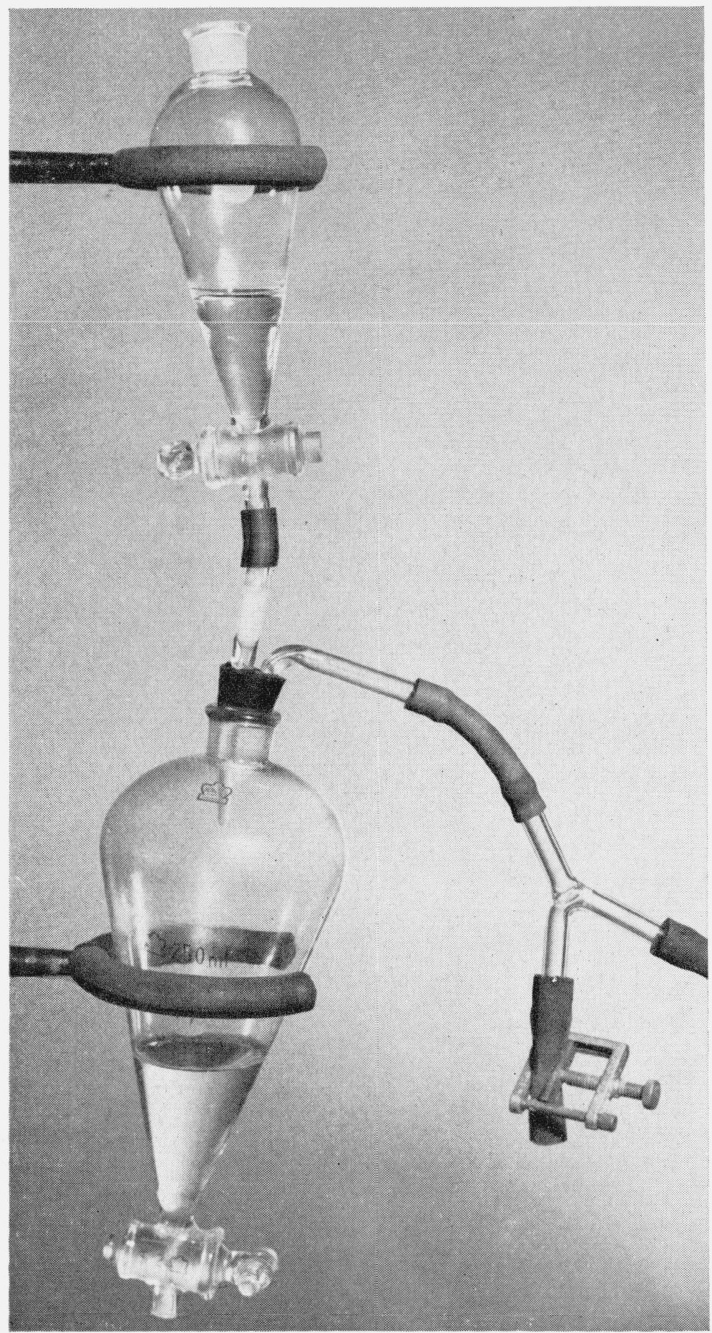

FiguRE 1. Arrangement for filtering.

\section{Reagents}

Sulfuric-Phosphoric-Perchloric Acid Mixture for Fuming. Add $100 \mathrm{ml}$ of sulfuric acid ${ }^{2}$ to $250 \mathrm{ml}$ of water, cool, add $100 \mathrm{ml}$ of phosphoric acid $(85 \%)$ and $50 \mathrm{ml}$ of perchloric acid $(70 \%)$. Mix thoroughly and cool.

Dithiol Solution. Dissolve $5 \mathrm{~g}$ of sodium hydroxide in $50 \mathrm{ml}$ of water and dilute to $500 \mathrm{ml}$. Add $1 \mathrm{~g}$ of 3,4 -dimercaptotoluene (dithiol), ${ }^{3}$ shake to dissolve

${ }^{2}$ If no dilumon is specified, the concentrated analytical reagent is meant Diluted hydrochloric acid $(1+1)$ denotes 1 vilume of concentrated hydrochloric acid, sp gr 1.18, diluted with 1 volume of water. Diluted sulfuric acid $(1+3)$ denotes 1 volume of concentrated sulfuric acid, sp gr 1.84, diluted with 3 volumes of water.

3 A satisfactory reagent of domestic manufacture is commercially available. it, and store in a refrigerator. Just before use, add $2 \mathrm{ml}$ of thioglycolic acid to $125 \mathrm{ml}$ of the dithiol solution, allow it to stand a few minutes, and filter through a close-textured paper. If a precipitate forms, which does not redissolve on a few minutes standing, too much thioglycolic acid has been added. Prepare a fresh portion, using slightly less thioglycolic acid. Use the turbid solution for the development of the tungsten color.

Stannous Chloride Solution. Dissolve $100 \mathrm{~g}$ of stannous chloride dihydrate and $5 \mathrm{mg}$ of copper chloride dihydrate in $400 \mathrm{ml}$ of diluted hydrochloric acid $(1+1)$ by heating on a steam bath. Cool and dilute to $500 \mathrm{ml}$ with diluted hydrochloric acid $(1+1)$.

Sulfuric-Sulfurous Acid Mixture. Saturate diluted sulfuric acid $(1+3)$ with sulfur dioxide gas.

Standard Tungsten Solution (1 $\mathrm{ml}=-1.00 \mathrm{mg}$ of tungsten). Transfer $0.1794 \mathrm{~g}$ of sodium tungstate dihydrate to a 100-ml volumetric flask, dilute to the mark with water, and mix. The sodium tungstate was purified and tested by the procedure suggested by Yagoda and Fales [20], though highpurity material is not required.

Standard Tungsten Solution (1 ml $\approx-100 \mu g$ of tungsten). Transfer exactly $10 \mathrm{ml}$ of standard tungsten solution ( $1 \mathrm{ml}=1.00 \mathrm{mg}$ of tungsten) to a $100-\mathrm{ml}$ volumetric flask, dilute to the mark with water and mix well. This solution should be prepared as needed.

\section{Procedure}

Transfer $0.200 \mathrm{~g}^{4}$ of the sample to a $125-\mathrm{ml}$ Erlenmeyer flask, add $10 \mathrm{ml}$ of aqua regia (3 parts of hydrochloric acid and 1 part of nitric acid), and heat gently until the sample dissolves. Add $20 \mathrm{ml}$ of the "fuming acid" mixture and 1 or 2 drops of hydrofluoric acid, boil until brown fumes have been expelled, evaporate to fumes, and fume the solution vigorously for a few minutes to remove the perchloric acid. Cool, add $25 \mathrm{ml}$ of diluted sulfuric acid $(1+3)$, and heat on a steam bath to dissolve insoluble salts. Cool, transfer the solution to a $100-\mathrm{ml}^{5}$ volumetric flask, and dilute to the mark with diluted sulfuric acid $(1+3)$.

Transfer $7.5 \mathrm{ml}$ of diluted sulfuric acid $(1+1)$, $5 \mathrm{ml}$. of sulfuric-sulfurous acid solution, and a suitable aliquot ${ }^{6}$ of the sample to a $60-\mathrm{ml}$ separatory funnel. Place the funnel in a water bath maintained at $30^{\circ}$ to $40^{\circ} \mathrm{C}$, add $5 \mathrm{ml}$ of dithiol solution, shake the solution for 5 to 10 seconds, and allow it to stand for 5 minutes. Cool, add $10 \mathrm{ml}$ of chloroform, shake it for 40 seconds, and allow the layers to separate. Drain and discard the chloroform layer. Repeat the extraction with $5 \mathrm{ml}$ of chloroform, finally discarding the chloroform layer. Filter the acid layer through glass wool (see fig. 1) in to a $250-\mathrm{ml}$ separatory funnel. Wash the 60-ml separatory

\footnotetext{
${ }^{4}$ For materials containing more than 0.5 percent of tungsten, use $0.100 \mathrm{~g}$ of the sample.

${ }_{5}^{5}$ For materials containing from 1 to 2 percent of tungsten, transfer to a $200-\mathrm{ml}$ volumetric flask.

${ }_{6}$ A suitable aliquot will contain up to $20 \mathrm{mg}$ of sample and less than $50 \mu \mathrm{g}$ of tungsten.
} 
funnel twice with 2- to 3-ml portions of diluted sulfuric acid $(1+3)$.

Place the $250-\mathrm{ml}$ separatory funnel in a steam bath for 10 minutes, cool in a water bath maintained at $30^{\circ}$ to $40^{\circ} \mathrm{C}$, add $2.5 \mathrm{ml}$ of dithiol solution, and shake for 5 to 10 seconds. Return the funnel to the water bath and allow it to stand for 5 minutes. Cool, add $5 \mathrm{ml}$ of chloroform, shake for 40 seconds, allow the layers to separate, drain and discard the chloroform layer. Repeat the extraction with another $5 \mathrm{ml}$ of chloroform, finally discarding the chloroform layer. Place the funnel in a steam bath and heat for 15 minutes. ${ }^{7}$

Add $50 \mathrm{ml}$ of hydrochloric acid and $5 \mathrm{ml}$ of stannous chloride solution to the funnel, return it to the steam bath, and heat for 3 minutes. Add $15 \mathrm{ml}$ of dithiol solution, mix well, and again heat on the steam bath for 10 minutes. Cool the solution in a cold-water bath, add exactly $20 \mathrm{ml}$ of butyl acetate from a pipet, shake for 20 seconds, and allow the layers to separate. Drain and discard the acid layer. Transfer the butyl acetate solution to a dry test tube and stopper the tube.

Transfer a suitable portion of the blank, or butyl acetate, to a $2-\mathrm{cm}$ absorption tube or cell and adjust the photometer to the initial setting, using a light band centered at approximately $635 \mathrm{~m} \mu$. While maintaining this photometer adjustment, take the photometric readings of the butyl acetate extract. ${ }^{8}$ Determine the percentage of tungsten from a calibration curve or table prepared as follows: Transfer $0.200 \mathrm{~g}$ of iron containing negligible quantities of tungsten and molybdenum (NBS Ingot Iron Standard Sample 55d was used) to a 125-ml Erlenmeyer flask, and continue as directed in the procedure for dissolving a sample. Add $10 \mathrm{ml}$ of sodium tungstate solution ( $1 \mathrm{ml} \sim-100 \mu \mathrm{g}$ of tungsten) to the flask just before adding the $20 \mathrm{ml}$ of "fuming acid" mixture, and continue with the procedure until the solution is diluted to volume in a $100-\mathrm{ml}$ volumetric flask (1 $\mathrm{ml}=10 \mu \mathrm{g}$ of tungsten). Prepare a blank iron solution by the same procedure, omitting the $10-\mathrm{ml}$ addition of sodium tungstate solution. Add $25 \mathrm{ml}$ of diluted sulfuric acid $(1+3)$ to five $250-\mathrm{ml}$ separatory funnels. Transfer none, 1.0, 2.0, 3.0, and $5.0 \mathrm{ml}$ of iron-tungsten solution ( $1 \mathrm{ml}=10 \mu \mathrm{g}$ of $\mathrm{W})$, and 5.0 , $4.0,3.0,2.0$, and none $\mathrm{ml}$, respectively, of blank iron solution ${ }^{9}$ to the funnels. Heat the solution on a steam bath, and continue with the development of the tungsten color, beginning with: "add $50 \mathrm{ml}$ of hydrochloric acid and $5 \mathrm{ml}$ of stannous chloride solution." Plot the photometric readings of the calibration solutions with respect to micrograms of tungsten. Beer's Law is obeyed under the conditions specified, and blanks are usually negligible.

7 The 15-minute heating period is required to remove the sulfur dioxide, which inhibits the development of the tungsten color; and to remove the chloroform, which would increase the volume of the solvent used to extract the tungstendithiol complex.

8 The absorbancy of this extract varies with temperature, about 0.2 percent per degree; measurements should be made within a range of $5^{\circ} \mathrm{C}$ if an accuracy of 1 percent is required.

$\theta$ The addition of blank solution is made to provide an adequate amount of iron for the complete development of the tungsten color.

\section{Discussion and Results}

The results obtained by the recommended procedure on a number of synthetic mixtures are given in table 1, as well as a few values obtained on mixtures containing copper, molybdenum, and tungsten, which were not filtered. Copper in 200- $\mu \mathrm{g}$ amounts does not interfere, as is shown in experment 1. Molybdenum in the absence of copper is removed by the chloroform extraction of the dithioltreated solution and does not interfere, as shown in experiments 2 and 3 . In mixtures containing both elements in appreciable quantities, the black precipitate formed by copper on the addition of dithiol appears to occlude molybdenum, and the extraction step does not completely remove molybdenum. The result is that on solution of the black copper precipitate during the development of the tungsten color, molybdenum is also present and causes a positive error, as shown in experiments 4 and 5. A filtration step was therefore added to the procedure.

TABLE 1. Results of determinations for tungsten by the recommended procedure in various synthetic mixtures

\begin{tabular}{|c|c|c|c|c|c|c|}
\hline \multirow{2}{*}{$\begin{array}{l}\text { Experi- } \\
\text { ment }\end{array}$} & \multirow{2}{*}{$\begin{array}{c}\text { Iron } \\
\text { added }\end{array}$} & \multirow{2}{*}{$\begin{array}{l}\text { Molyb- } \\
\text { denum } \\
\text { added }\end{array}$} & \multirow{2}{*}{$\begin{array}{l}\text { Copper } \\
\text { added }\end{array}$} & \multicolumn{3}{|c|}{ Tungsten } \\
\hline & & & & Added & Found & Difference \\
\hline & $m g$ & $\mu g$ & $\mu g$ & $\mu g$ & $\mu g$ & $\mu g$ \\
\hline $1^{\mathrm{a}} \ldots \ldots$ & 10 & & 200 & & 0.1 & +0.1 \\
\hline $2^{\mathrm{a}}$ & 10 & 30 & - n. & 20.0 & 20.0 & 0 \\
\hline $3^{\mathrm{a}}$ & 20 & 50 & 300 & 50.0 & 49.5 & -.5 \\
\hline $\begin{array}{l}4^{\mathrm{a}} \ldots \\
5^{\mathrm{a}}\end{array}$ & $\begin{array}{l}10 \\
10\end{array}$ & $\begin{array}{l}50 \\
30\end{array}$ & $\begin{array}{l}200 \\
200\end{array}$ & 20.0 & $\begin{array}{r}6.4 \\
23.5\end{array}$ & $\begin{array}{l}+6.4 \\
+3.5\end{array}$ \\
\hline $6 \ldots$ & $\ldots$ & 50 & - & 20.0 & 19.4 & -0.6 \\
\hline $7 \ldots$ & 1 & 50 & - & 20.0 & 19.8 & -.2 \\
\hline $8 \ldots$ & 5 & 50 & _..... & 20.0 & 19.8 & -.2 \\
\hline $9 \ldots \ldots$ & 20 & 50 & ...... & 20.0 & 19.9 & -.1 \\
\hline $10 \ldots$ & 30 & 50 & -..... & 20.0 & 20.2 & +.2 \\
\hline 11. & 50 & 50 & - n- & 20.0 & 24.5 & +4.5 \\
\hline 12 & 100 & 50 & -.... & 20.0 & 33.1 & +13.1 \\
\hline $13 \ldots$ & 100 & & & 20.0 & 19.8 & -0.2 \\
\hline $14 \ldots$ & 10 & 50 & 200 & . & 0.5 & +.5 \\
\hline $15 \ldots$ & 10 & 50 & -...... & 1.0 & 1.0 & .0 \\
\hline 16 & 10 & 50 & & 2. 0 & 1.9 & -.1 \\
\hline $17 \ldots$ & 20 & 50 & 200 & 5. 0 & 5. 1 & +.1 \\
\hline $18 \ldots$ & 20 & 50 & 200 & 20.0 & 20.0 & .0 \\
\hline $19 \ldots$ & 20 & 50 & 50 & 20.0 & 19.7 & -.3 \\
\hline $20 \ldots$ & 24 & 100 & 10 & 20.0 & 20.0 & .0 \\
\hline $21 \ldots \ldots$ & 20 & 50 & 200 & 50.0 & 49.8 & -.2 \\
\hline $22 \ldots$ & 20 & 50 & -.... & 50.0 & 49.5 & -.5 \\
\hline
\end{tabular}

a Not filtered to remove copper precipitate.

Iron also inhibits the removal of molybdenum by the dithiol extraction step, and the extent of this interference is shown by experiments 7 to 12. About $30 \mathrm{mg}$ of iron can be tolerated satisfactorily in the presence of molybdenum, or combinations of molybdenum and copper. The high sensitivity of the tungsten-dithiol reaction allows small amounts (0.005 percent or more) of tungsten to be determined quite satisfactorily, as shown by experiments 14 to 22. Experiment 6 shows the necessity for the presence of a small quantity of iron; a low recovery is obtained in the absence of iron [2]. As is shown by experiment 13, the accuracy of the tungsten determination is satisfactory in the presence of considerable iron if molybdenum is absent. A few experiments on 100-mg samples of NBS Ingot Iron 
Standard Sample 55d indicated that an additional quantity (7 to $8 \mathrm{ml}$ ) of sulfuric-sulfurous acid solution and of thioglycolic acid $(0.2 \mathrm{ml})$ helped in the removal of small amounts of molybdenum, and that this standard, used in preparing calibration curves, contains tungsten in amounts of the order of 1 or 2 ppm. A few experiments, in which copper and molybdenum were largely removed by treatment with hydrogen sulfide and filtration, indicated values of the same order.

The reaction of molybdenum with dithiol also appears to be sensitive to temperature. Although this particular point was not studied extensively, the reaction is too slow in the presence of iron at $10^{\circ}$ to $15^{\circ} \mathrm{C}$ to be useful. The reaction temperature of $30^{\circ}$ to $40^{\circ} \mathrm{C}$ was selected on the basis of convenience and a reasonable time for the removal of molybdenum.

Because the only difficulty encountered was the occasional incomplete extraction of molybdenum at the proper point (a complaint common to many of the published procedures using dithiol), photometric readings were also taken at approximately $720 \mathrm{~m} \mu$ to detect a failure of this sort. A change in ratio of the absorbancy at $635 \mathrm{~m} \mu$ to that at $720 \mathrm{~m} \mu$ will indicate the presence of molybdenum; in fact, a procedure has been suggested [15] for the simultaneous determination of molybdenum and tungsten by photometric measurements at two different wavelengths. Dithiol and thioglycolic acid were ordered in small quantities and stored in a refrigerator. Difficulties were not encountered with prepared solutions of these reagents if they were stored in the refrigerator and used witbin a few days.

During a study of the thiocyanate photometric method for tungsten it was found that a relatively rapid and complete reduction of tungsten by stannous chloride in strong hydrochloric acid solution occurred in the presence of a trace of copper. Because this reduction is also required in the dithiol procedure, a similar technique was applied. Variations in the recovery of tungsten with several time intervals for color development, and with several amounts of stannous chloride and dithiol solutions are illustrated in figure 2. The conditions selected in the recommended procedure are about the minimum required to give a satisfactory development of the tungstendithiol complex in the range 1 to $50 \mu \mathrm{g}$ of tungsten. The volume at the beginning of the color-development step is usually about $30 \mathrm{ml}$, but in handling small percentages of tungsten requiring larger sample aliquots, a larger volume is usually obtained. Volumes of up to $75 \mathrm{ml}$, containing $20 \mu \mathrm{g}$ of tungsten, have been satisfactorily handled, as shown in figure 2 .

A few experiments in which a second extraction with butyl acetate was made, indicate the tungstendithiol complex is completely (more than 99 percent) extracted in one treatment. The results of experiments in which extra dithiol is added to an extracted solution, followed by reheating, cooling, and extraction of any additional complex with butyl acetate, indicate that the reaction is essentially complete in the 10-minute period specified in the procedure. A

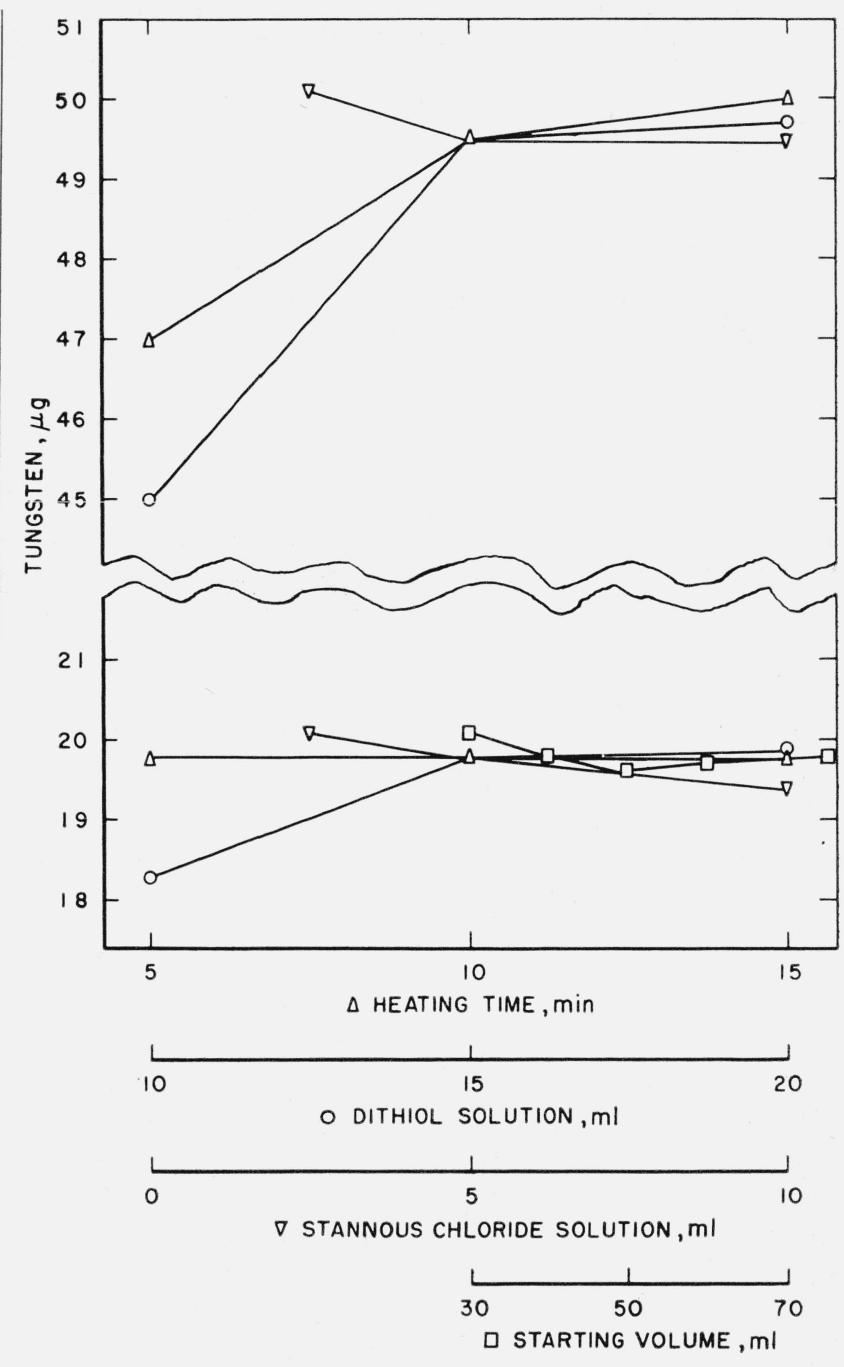

Figure 2. Effect of variables on the development of the tungsten dithiol complex.

small amount (less than 1 percent) of the tungsten present is lost during the chloroform extraction of molybdenum. This loss was checked by the evaporation of several combined chloroform extracts with sulfuric acid and hydrogen peroxide, followed by a determination of the tungsten present in the resulting: solution, as described in the recommended procedure.

The results obtained on a few of the National Bureau of Standards Standard Samples of steel are shown in table 2. The values for NBS Standard Samples 159, 123, 160, and 101d have not been previously determined, because a satisfactory method for the determination of such small quantities of tungsten in these types of alloys has not been available. The values for NBS Standard Samples $123 \mathrm{~b}$, $155,153,134,134 \mathrm{a}$ and the NBS Spectrographic Steel Standards 442,443 , and 444 show satisfactory agreement, considering the complexity of the materials and of the procedures used in the original analyses. The higher values given for the NBS Spectrographic Steel Standard Samples 446 and 846 
TABLE 2. Results of determinations for tungsten by the recommended procedure in various National Bureau of Standards Standard Samples

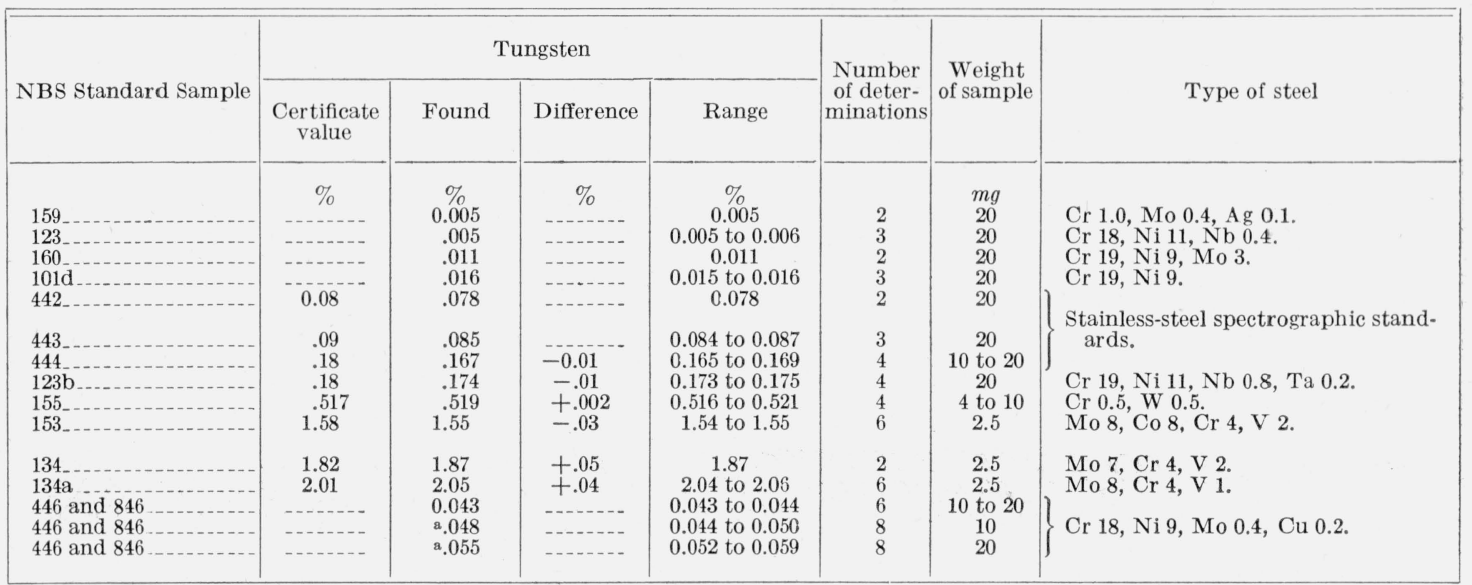

a Not filtered to remove copper precipitate.

where the copper precipitate is not removed demonstrate the range of error that will be encountered, and the necessity for the steps in the procedure that allow for more than residual amounts of copper and molybdenum. The ranges given in table 2 show the excellent precision of the method.

Table 3 shows tests made with 15 elements mentioned as reacting with dithiol or otherwise interfering in the detection of tungsten. As will be seen, none of these elements in the amounts tested inhibit the removal of molybdenum or hinder the development of the tungsten color, and quite satisfactory recoveries of tungsten are obtained. Satisfactory determinations were also obtained in the presence of $500 \mathrm{mg}$ of citric or tartaric acid.

TABLE 3. Results of determinations for tungsten by the recommended procedure in the presence of possible interfering elements

\begin{tabular}{|c|c|c|c|c|c|c|}
\hline \multirow{2}{*}{$\begin{array}{c}\text { Experi- } \\
\text { ment }\end{array}$} & \multirow{2}{*}{$\begin{array}{l}\text { Other ele- } \\
\text { ment added }\end{array}$} & \multirow{2}{*}{$\begin{array}{l}\text { Iron } \\
\text { added }\end{array}$} & \multirow{2}{*}{$\begin{array}{l}\text { Molyb- } \\
\text { denum } \\
\text { added }\end{array}$} & \multicolumn{3}{|c|}{ Tungsten } \\
\hline & & & & Added & Found & Difference \\
\hline $\begin{array}{l}1 \ldots \\
2 \ldots \\
3 \\
4-\ldots \\
5\end{array}$ & $\begin{array}{l}\mu g \\
200 \mathrm{Sb} \\
200 \mathrm{As} \\
200 \mathrm{Bi} \\
5,000 \mathrm{Cr} \\
2,000 \mathrm{Co}\end{array}$ & $\begin{array}{l}m g \\
10 \\
10 \\
10 \\
10 \\
10\end{array}$ & $\begin{array}{l}\mu g \\
50 \\
50 \\
50 \\
50 \\
50\end{array}$ & $\begin{array}{c}\mu g \\
20.0 \\
20.0 \\
20.0 \\
20.0 \\
20.0\end{array}$ & $\begin{array}{c}\mu g \\
19.9 \\
19.8 \\
19.9 \\
19.8 \\
20.2\end{array}$ & $\begin{array}{c}\mu g \\
-0.1 \\
-.2 \\
-.1 \\
-.2 \\
+.2\end{array}$ \\
\hline $\begin{array}{l}6 \\
7-\ldots- \\
8-\ldots \\
9-\ldots \\
10\end{array}$ & $\begin{array}{l}2,000 \mathrm{Co} \\
200 \mathrm{~Pb} \\
200 \mathrm{Mn} \\
200 \mathrm{Hg} \\
4,400 \mathrm{Ni}\end{array}$ & $\begin{array}{l}10 \\
10 \\
10 \\
10 \\
10\end{array}$ & $\begin{array}{l}50 \\
50 \\
50 \\
50 \\
50\end{array}$ & $\begin{array}{l}20.0 \\
20.0 \\
20.0 \\
20.0 \\
20.0\end{array}$ & $\begin{array}{l}19.9 \\
19.8 \\
19.9 \\
19.8 \\
19.9\end{array}$ & $\begin{array}{l}-.1 \\
-.2 \\
-.1 \\
-.2 \\
-.1\end{array}$ \\
\hline $\begin{array}{l}11 \\
12 \\
13 \\
14 \\
15\end{array}$ & $\begin{array}{l}600 \mathrm{Pt} \\
200 \mathrm{Re} \\
200 \mathrm{Se} \\
200 \mathrm{~g} \\
2,000 \mathrm{Sn}\end{array}$ & $\begin{array}{l}10 \\
10 \\
10 \\
12 \\
10\end{array}$ & $\begin{array}{l}50 \\
50 \\
50 \\
50 \\
50\end{array}$ & $\begin{array}{l}20.0 \\
20.0 \\
20.0 \\
20.0 \\
20.0\end{array}$ & $\begin{array}{l}19.8 \\
19.8 \\
19.9 \\
19.9 \\
20.1\end{array}$ & $\begin{array}{l}-.2 \\
-.2 \\
-.1 \\
-.1 \\
+.1\end{array}$ \\
\hline $16_{-}$ & $200 \mathrm{~V}$ & 10 & 50 & 25.0 & 24.9 & -.1 \\
\hline
\end{tabular}

The reaction of some of these elements with dithiol may be of interest. The rhenium compound with dithiol is visually indistinguishable from that of molybdenum. Bismuth forms a brown precipitate, which is extracted by chloroform; tin behaves similarly except that the precipitate is red. Silver forms a black precipitate and, like copper, is removed by filtration. Selenium behaves similarly, forming a brown or pink precipitate. Platinum added as chloroplatinate divides, a part being removed by filtering the brown precipitate formed. The remainder reacts on the addition of stannous chloride during the development of the tungsten color to form a yellow complex, which is extracted by butyl acetate. An "off-colored" solution is obtained, but the extraneous color does not interfere when the absorbancy of the solution is measured at $635 \mathrm{~m} \mu$ as directed. Cobalt forms a blue complex on the addition of hydrochloric acid, but in the amount used in the test does not appear to interfere. The remaining elements did not give visible reactions in the concentrations tested.

\section{References}

[1] S. H. Allen and M. B. Hamilton, Anal. Chim. Acta \%, 483 (1952).

[2] S. H. Allen and M. B. Hamilton, Anal. Chim. Acta. \%, 487 (1952).

[3] B. Bagshaw and R. J. Truman, Analyst 72, 189 (1947).

[4] C. F. Bickford, W. S. Jones and J. S. Keene, J. Am. Pharm. Assoc. 37, 255 (1948).

[5] C. E. Crouthamel and C. E. Johnson, Anal. Chem. 26, 1288 (1954).

[6] P. Greenberg, Anal. Chem. 29, 896 (1957).

[7] J. H. Hamence, Analyst 65, 152 (1940).

[8] W. H. Hillebrand, G. E. F. Lundell, H. A. Bright and J. I. Hoffman, Applied inorganic analysis, 2d ed., p. 686 (J. Wiley \& Sons, Inc., New York, N. Y., 1953).

[9] L. Ikenberry, J. Leo Martin and W. J. Boyer, Anal. Chem. 25, 1340 (1953).

[10] C. M. Johnson, Iron Age 15\%, No. 14, 66-69 (1944)

[11] Methods of Analysis Committee, J. Iron Steel Inst. 17\%, 413 (1952).

[12] Methods of Analysis Committee, J. Iron Steel Inst. 178, 267 (1954).

[13] C. C. Miller and A. J. Lowe, J. Chem. Soc. 40, 1262 (1940).

[14] C. C. Miller, Analyst 69, 109 (1944).

[15] A. A. North, Analyst 81, 660 (1956).

[16] R. Pemberton, Analyst $\mathbf{7 \% ,} 290$ (1952).

[17] C. S. Piper and R. S. Beckwith, J. Soc. Chem. Ind. (London), 6\%, 374 (1948).

[18] H. G. Short, Analyst 76, 710 (1951).

[19] E. J. Vaughan and C. Whalley, J. Iron Steel Inst. 155, 549 (1947).

[20] H. Yagoda and H. A. Fales, J. Am. Chem. Soc. 58, 1495 (1936). 


\section{Appendix}

\subsection{Determination of Tungsten in Titanium}

At the request of the Watertown Arsenal Task Force for the determination of tungsten in titanium metal, tungsten was determined by the dithiol procedure in their samples WA-22 and WA-8. Because titanium phosphate in quantity is not very soluble in sulfuric-phosphoric acid mixtures, the procedure was modified to provide a suitable solution for titanium-base alloys.

\subsection{Modified Procedure}

Transfer $0.2 \mathrm{~g}$ of the sample to a 125-ml Erlenmever flask, add $20 \mathrm{ml}$ of diluted sulfuric acid $(1+3)$ and 2 or 3 drops of hydrofluoric acid. Heat gently until the sample is dissolved and add, drop by drop (about 6 to 8 drops are required) hydrogen peroxide (30 percent) until the purple color of reduced titanium is discharged and a permanent yellow color of peroxidized titanium is formed. Evaporate the solution to fumes, and cool. Add $50 \mathrm{ml}$ of diluted sulfuric acid $(1+3)$ containing a gram of citric acid, and digest a few minutes to obtain a clear solution. Cool, transfer the solution to a $100-\mathrm{ml}$ volumetric flask, and dilute to the mark with diluted sulfuric acid $(1+3)$.

Transfer a suitable aliquot, as indicated in table 4 , of the prepared sample solution to a $250-\mathrm{ml}$ separatory funnel. Add $0.2 \mathrm{ml}$ of ferric sulfate solution (10 $\mathrm{mg}$ of iron per $\mathrm{ml}$ of diluted sulfuric acid $(1+9)$ ), $7.5 \mathrm{ml}$ of diluted sulfuric acid $(1+1)$, and $5 \mathrm{ml}$ of dilute sulfuric acid $(1+3)$ saturated with sulfur dioxide, and complete the determination as described for steel. Because most titanium alloys contain little copper or other similarly reacting elements in suffi- cient amount to require a filtration, this step was omitted on these samples.

TABLE 4. Results of determinations for tungsten in titaniumbase materials

\begin{tabular}{|c|c|c|c|c|c|c|}
\hline \multirow{2}{*}{ Sample } & \multicolumn{3}{|c|}{ Tungsten } & \multirow{2}{*}{$\begin{array}{l}\text { Molyb- } \\
\text { denum } \\
\text { added }\end{array}$} & \multirow{2}{*}{$\begin{array}{c}\text { Iron } \\
\text { added }\end{array}$} & \multirow{2}{*}{$\begin{array}{l}\text { Titanium } \\
\text { present }\end{array}$} \\
\hline & Added & Found & Difference & & & \\
\hline $\begin{array}{ll}1_{3} & \cdots \\
2 & \cdots \\
3 & -\cdots \\
4 & \cdots \\
5_{-} & \cdots \\
6 & \cdots\end{array}$ & $\begin{array}{c}\mu g \\
10.0 \\
10.0 \\
10.0 \\
50.0 \\
50.0 \\
50.0\end{array}$ & $\begin{array}{r}\mu g \\
10.1 \\
10.2 \\
10.0 \\
49.7 \\
49.5 \\
48.2\end{array}$ & $\begin{array}{r}\mu g \\
+0.1 \\
+.2 \\
.0 \\
-.3 \\
-.5 \\
-1.8\end{array}$ & $\begin{array}{c}\mu g \\
-50 \\
50 \\
-\end{array}$ & $\begin{array}{c}m g \\
2 \\
2 \\
- \\
-2 \\
2 \\
-\end{array}$ & $\begin{array}{l}m g \\
20 \\
20 \\
20 \\
10 \\
10 \\
10\end{array}$ \\
\hline W A-8_. & $\%$ & $\begin{array}{c}\% \\
0.372 \\
.368 \\
.374 \\
.371\end{array}$ & $\begin{array}{c}\% \\
\end{array}$ & - & $\begin{array}{l}2 \\
2 \\
2 \\
2\end{array}$ & $\begin{array}{l}10 \\
10 \\
10 \\
10\end{array}$ \\
\hline W A-22_ & - & $\begin{array}{l}.057 \\
.056 \\
.056 \\
.056\end{array}$ & - & - & $\begin{array}{l}2 \\
2 \\
2 \\
2\end{array}$ & $\begin{array}{l}20 \\
20 \\
20 \\
20\end{array}$ \\
\hline
\end{tabular}

The results obtained on a few synthetic mixtures, and on two samples, are given in table 4. Titanium was added to the six synthetic mixtures as portions of a titanium solution prepared from National Bureau of Standards Standard Sample 173, a 6-percent aluminum, 4-percent vanadium titanium-base alloy containing approximately 0.001 percent of tungsten. The values obtained by the Watertown Task Force, by a double $\alpha$-benzoinoxime precipitation and hydroquinone photometric method, average about 0.40 percent of tungsten for sample WA-8 and approximately 0.05 to 0.06 percent for sample WA-22. Greenberg [6] has reported 0.38 and 0.055 percent of tungsten for the same samples by a dithiol procedure.

Washington, June 12, 1957. 